\title{
ANALISIS KELAYAKAN INVESTASI ALAT PULLER PADA MESIN CORE UNTUK MENURUNKAN CYCLE TIME DI CV XYZ
}

\author{
Rudy Bowo Leksono, Tedjo Sukmono \\ Program Studi Teknik Industri \\ Universitas Muhammadiyah Sidoarjo, Sidoarjo, Jawa Timur 61271 \\ rudy.bowoleksono@yahoo.com
}

\begin{abstract}
Abstrak
Strategi global purchasing yang diterapkan oleh perusahaan produsen kendaraan bermotor di Indonesia telah memaksa suplier suplier lokal untuk berimprovisasi dan berinovasi dalam proses produksinya agar tetap bisa bersaing dengan kompetitor luar negeri. CV XYZ adalah sebuah perusahaan pengecoran besi yang memproduksi berbagai macam komponen otomotif. Perusahaan yang berlokasi di Kabupaten Pasuruan ini menjual hasil produksinya ke beberapa peusahaan produsen kendaraan bermotor di tanah air. Dalam upayanya meningkatkan daya saing, perusahaan ini membuat program cost reduction untuk menurunkan biaya produksinya. Salah satu upaya yang dilakukan adalah adanya usulan investasi alat puller yang dipasang di mesin core untuk menurunkan cycle time. Sebelum usulan investasi ini direalisasikan, perusahaan menginginkan dilakukan analisis kelayakan terlebih dulu. Dari hasil pengolahan data diperoleh besarnya biaya yang harus dikeluarkan oleh perusahaan untuk biaya investasi dan biaya operasional adalah Rp 16.203.923 sedangkan manfaat yang akan diterima sebesar Rp 29.547.013. NetPresent Value (NPV) nya sebesar Rp 1.416.191, Internal Rate Return (IRR) 16,08\% dengan MARR yang ditetapkan perusahaan 15\% sedangkan Pay BackPeriod (PBP) nya 1tahun 10,48 bulan. Dengan hasil seperti ini berarti investasi alat puller ini layak untuk direalisasikan.
\end{abstract}

Kata kunci: Alat puller, ekonomi teknik, analisis kelayakan

\begin{abstract}
Global purchasing strategy was implemented by the automotive manufacturers company in Indonesia has forced local suppliers to improvise and innovate in their production processes in order to remain able to compete with foreign competitors. $C V X Y Z$ is an iron foundry company that produces a wide range of automotive components . Companies was located in Pasuruan, East Java, sells its products to some of the Vendor automotive manufacturers in the country. In its efforts to improve competitiveness, the company is making cost reduction program to reduce the cost of production. One of the efforts is proposed investment puller equipment mounted in the core machine to reduce its cycle time. Before the proposed investment is realized, the company wants to do a feasibility analys first. From the data processing obtained the amount of costs to paid by the company for the cost of investment and operational cost is Rp 16,203,923 and the revenue that will be received is $R p$ 29,547,013. Net Present Value ( NPV ) of its Rp 1,416,191, Internal Rate of Return ( IRR ) 16,08\% which $15 \%$ MARR has determined by the company. Pay Back Period ( PBP ) is 1 year 10.48 a month. This results indicates that puller equipmentinvestment is feasible to be realized.
\end{abstract}

Key words: puller equipment, economic tecknik, feasibility analys

\section{PENDAHULUAN}

Strategi global purchasing untuk mendapatkan resources yang dilakukan oleh berbagai perusahaan multinasional dibidang otomotif di Indonesia telah memaksa produsen produsen lokal untuk berupaya keras supaya tetap bisa bersaing dengan kompetitornya. Dengan sistem persaingan yang seperti ini, menyebabkan harga barang akan dikendalikan oleh pelanggan karena sesuai dengan hukum pasar yaitu jika suply meningkat sedangkan permintaan turun maka harga akan turun (Giatman, 2006). Salah satu hal yang harus dilakukan produsen produsen lokal adalah menjaga kualitas barang sesuai persyaratan pelanggan dengan tetap memberikan harga yang kompetitif serta ketepatan pengiriman barang sesuai dengan jadwal yang sudah ditentukan. 
CV XYZ adalah sebuah perusahaan pengecoran logam utamanya logam besi yang memproduksi berbagai macam komponen otomotif. Berbagai macam model spare part kendaraan bermotor dan mesin industri yang terbuat dari besi cor bisa dihasilkan dari perusahaan ini. CylinderLiner adalah salah satunya. Cylinder liner ini menjadi produk unggulan diperusahaan karena menempati urutan teratas dalam hal jumlah produksinya yaitu sekitar $60 \%$ dari total keseluruhan produksinya.

Untuk memenuhi pesanan tersebut, CV XYZ mengoperasikan beberapa unit mesin core making, dengan tujuan agar jumlah core yang dibutuhkan tetap seimbang dengan jumlah core yang dihasilkan. Untuk meningkatkan hasil produksi mesin core making, ada beberapa usulan perbaikan yang layak dipertimbangkan. Usulan perbaikan yang diajukan oleh tim Continuous Improvement adalah dengan menambah alat puller yang dipasang pada mesin core making. Tujuan penambahan alat puller ini adalah untuk menghilangkan beberapa elemen kerja kategori non value added dalam proses pembuatan core sehingga cycle time pembuatan core menjadi berkurang.

\section{TINJAUAN PUSTAKA}

Sebelum usulan penambahan alat tersebut direalisasikan, perlu dilakukan analisis kelayakan dari sisi ekonomi. Menurut Kasmir dkk (2007) dalam Manope (2014) menyatakan bahwa setiap perusahaan atau investor sebelum melakukan investasi harus melakukan studi kelayakan terlebih dulu. Studi kelayakan ini salah satunya bertujuan untuk menghindari resiko atau kerugian yang akan timbul. Masih menurut Kasmir dkk, kelayakan berarti manfaat yang akan diterima nilainya lebih besar dari investasi yang sudah dikeluarkan. Hasil analisis kelayakan bisa digunakan sebagai bahan pertimbangan untuk mengambil keputusan (Ibrahim 2009, dalam Manope 2014).Dengan melakukan analisis kelayakan, diharapkan CV XYZ mempunyai gambaran yang jelas mengenai manfaat yang akan diterima dan juga biaya biaya yang harus dikeluarkan jika merealisasikan usulan penambahan alat puller ini.Dengan analisis ini jugabisa diketahui tingkat kelayakan proyek yang diusulkan oleh tim continuous improvement. Adanya alat puller ini diharapkan bisa menurunkan waktu baku pembuatan core sehingga proses pembuatannya menjadi lebih cepat.

Waktu baku adalah waktu yang digunakan untuk menyelesaikan suatu pekerjaan oleh seorang pekerja yang memiliki tingkat kemampuan rata rata. Dengan pengertian ini berarti waktu baku bisa digunakan untuk merencanakan penjadwalan kerja sampai seberapa lama pekerjaan tersebut bisa diselesaikan dan berapa hasil yang bisa diperoleh (Wignjosoebroto,2006).

Untuk menghitung besarnya waktu baku dengan menggunakan langkah langkah sebagai berikut:

\section{A. Menentukan waktu siklus}

Waktu siklus atau cycle time adalah waktu yang diperlukan untuk membuat satu unit produk pada satu stasiun kerja (Purnomo 2003 dalam Rinawati 2013). Menurut Sutalaksana 2006 dalam Rahman 2013, untuk menghitung besarnya waktu siklus sesuai dengan rumus:

$$
\mathrm{Ws}=\overline{\overline{\mathrm{x}}} 2
$$

\section{B. Menentukan waktu normal}

$$
\mathrm{Wn}=\mathrm{Ws} \mathrm{xp}
$$

dimana: $\mathrm{p}=$ faktor penyesuaian.

Faktor ini diperhitungkan bila operator bekerja dengan tidak wajar sehingga hasil perhitungan waktu perlu disesuaikan untuk mendapatkan waktu penyelesaian pekerjaan yang normal. Terdapat beberapa cara untuk menentukan faktor penyesuaian (Sutalaksana 2006 dalam Rahman 2013) diantaranya adalah cara Westinghouse. Cara ini terdiri dari 4 faktor yaitu keterampilan, usaha, kondisi dan yang terakhir adalah konsistensi. 


\section{Menentukan Waktu baku}

dimana: $\mathrm{a}=$ kelonggaran (allowance)

$$
\mathrm{Wb}=\mathrm{Wn} \times(1+\mathrm{a})
$$

Kelonggaran diberikan kepada operator untuk menyelesaikan pekerjaannya. Kelonggaran ini diberikan untuk kebutuhan pribadi, menghilangkan rasa lelah, dan gangguan yang mungkin terjadi yang tidak dapat dihindarkan oleh operator.

Dengan berubahnya Waktu Baku setelah investasi alat puller maka akan berpengaruh dengan Harga Pokok Produksi core tersebut.Harga Pokok Produksi (HPP) adalah kumpulan dari berbagai biaya produksi yang terdiri dari biaya bahan baku, biaya tenaga kerja langsung dan biaya overhead (Nurlela, 2007 dalam Hendrich, 2013). Perubahan HPP ini hanya terjadi pada komponen biaya tenaga kerja langsung dan biaya overheadnya sedangkan pada biaya bahan baku tetap.

Dalam analisis kelayakan investasi, untuk membandingkan antara besarnya manfaat yang diterima dengan biaya yang dikeluarkan dihitung dengan menggunakan ekonomi teknik yang meliputi Net Present Value, Internal Rate Return, Pay Back Period serta Analisa Sensitifitas.

Net present value merupakan perbandingan antara PV kas bersih dan PV investasi selama umur teknis (Kasmir dkk, 2014).

Net present value merupakan perbedaan antara nilai sekarang dari keuntungan dan biaya biaya yang akan dikeluarkan (Sudong 2002, dalam Kusuma dkk, 2014). Menurut Pujawan 2012,

Atau

$$
\mathrm{NPV}=\mathrm{PW} \mathrm{R}-\mathrm{PW} \mathrm{E}
$$

$$
\sum_{t=0}^{n} R(P / F, i \%, t)-\sum_{t=0}^{n} E(P / F, i \%, t)
$$

Dimana:

PW R = Nilai present worth dari semua pemasukan

PW E = Nilai present worth dari semua pengeluaran

$\mathrm{R}=$ Penerimaan netto pada periode $\mathrm{t}$

$\mathrm{E}=$ Pengeluaran netto pada periode $\mathrm{t}$ termasuk investasi awal

Untuk mengetahui tingkat kelayakan dari usaha yang ingin dijalankan bisa diketahui dengan kriteria yaitu:Jika NPV > 0 maka investasi dianggap layak. NPV $<0$ maka investasi dianggap tidak menguntungkan ( Giatman, 2006).

Metode Internal Rate Return adalah suatu metode yang akan digunakan untuk mencari tingkat suku bunga terhadap pengembalian modal disaat NPV sama dengan 0 (Giatman,2006). Pujawan (2012) menyatakan IRR adalah tingkat bunga yang menyebabkan keseimbangan antara semua pengeluaran dan pemasukan pada periode tertentu. Suatu usaha dikatakan layak jika nilai IRR lebih tinggi dari MARR (minimum atractive rate of return).

$$
\mathrm{IRR}=\mathrm{PW} \text { penerimaan }-\mathrm{PW} \text { pengeluaran }=0
$$

atau

$$
\sum_{t=0}^{n} R\left(\frac{P}{F}, i \%, t\right)-\sum_{t=0}^{n} E\left(\frac{P}{F}, i \%, t\right)=0
$$

Dimana $\mathrm{R}$ = penerimaan netto yang terjadi pada periode $\mathrm{t}$

$\mathrm{E}=$ Pengeluaran netto yang terjadi pada periode ke $\mathrm{t}$ termasuk investasi awal (Pujawan, 2012).

Pay Back Periode adalah jumlah periode yang diperlukan untuk mengembalikan ongkos investasi awal dengan tingkat pengembalian tertentu (Pujawan, 2012).

Erlina 2006 dalam Kusuma (2014) menyatakan bahwa pay back periode adalah waktu minimum yang dibutuhkan untuk mengembalikan investasi awal dalam bentuk aliran kas yang didasarkan dari total penerimaan dikurangi total semua biaya.Rumusan untuk mencari PayBack Periode adalah: 


$$
\mathrm{PBP}=\mathrm{t}+\frac{b-c}{d-c} \times 12 \text { bulan }
$$

Dimana : $\mathrm{t}$ adalah tahun terakhir dimana jumlah cash inflow sebelum menutup investasi awal

$$
\begin{aligned}
& \mathrm{b}=\text { Investasi Awal } \\
& \mathrm{c}=\text { Kumulatif cash inflow tahun } \mathrm{t} \\
& \mathrm{d}=\text { Kumulatif cash flow pada tahun } \mathrm{t}+1
\end{aligned}
$$

( Sumber Suliyanto, 2010 dalam Simarmata 2015)

Kriteria penentuan layak atau tidaknya suatu investasi berdasarkan metode pay back periode ini adalah jika PBP < nilai ekonomis suatu peralatan yang akan direalisasikan maka investasi tersebut layak untuk dilanjutkan. Tetapi jika PBP lebih besar dari nilai ekonomis peralatan maka investasi dianggap tidak layak.

Analisa sensitifitas digunakan untuk mengetahui sejauh mana perubahan paramater dalam investasi berdampak pada hasil yang sudah dihitung sebelumnya yang diakibatkan oleh perubahan situasi dan kondisi selama umur teknis.(Giatman, 2006). Analisa sensitifitas dilakukan dengan mengubah nilai dari suatu parameter pada suatu waktu untuk selanjutnya dilihat bagaimana pengaruhnya terhadap akseptabilitas suatu alternatif investasi(Pujawan, 2012).

\section{METODOLOGI PENELITIAN}

Metodologi penelitian yang dilakukan dalam penelitian ini adalah:

A. Pendahuluan. Melakukan wawancara dengan pihak perusahaan untuk mengetahui kondisi awal perusahaan dan mengumpulkan informasi untuk menemukan masalah yang sedang dihadapi untuk dijadikan bahan penelitian

B. Studi Lapangan. Melakukan observasi terhadap obyek yang akan diteliti dengan melakukan wawancara dengan operator dan pihak terkait guna mengetahui kondisi obyek penelitian

C. Studi Literatur. Mencari informasi tambahan dari sumber sumber lain yang berupa buku, jurnal dan sumber lainnya yang akan digunakan sebagai referensi dalam melakukan pembahasan

D. Pengumpulan Data.Pengumpulan data dilakukan melalui dua cara yaitu

1. Data primer yaitu melakukan pengamatan sendiri terhadap obyek yang diteliti untuk mendapatkan informasi

2. Data skunder yaitu proses pengumpulan data dengan cara meminta data atau informasi yang berhubungan dengan obyek penelitian kepada pihak perusahaan

E. Pengolahan Data.Melakukan pengolahan dari bermacam macam data yang sudah dikumpulkan dengan merujuk pada sumber sumber kepustakaan yang dijadikan referensi

F. Analisa Hasil. Melakukan analisa terhadap hasil hasil pengolahan data

G. Kesimpulan. Melakukan penarikan kesimpulan atas analisa hasil 


\section{HASIL DAN PEMBAHASAN}

Tahapan awal yang dilakukan adalah membandingkan waktu siklus dan proses pembuatan core sebelum penambahan alat dan sesudah penambahan alat.

\begin{tabular}{|c|c|c|c|c|}
\hline \multirow[t]{2}{*}{ No } & \multirow[t]{2}{*}{ Nama Proses } & \multicolumn{2}{|c|}{ Waktu (detik) } & \multirow[t]{2}{*}{ Keterangan } \\
\hline & & Sebelum & Sesudah & \\
\hline 1 & Menutup corebox & 2,8 & 2,8 & \\
\hline 2 & Menggeser Blow tank ke core box & 2,1 & 2,1 & \\
\hline 3 & Menurunkan Blow Head & 1,2 & 1,2 & \\
\hline 4 & Meniup pasir ke core box & 4.2 & 4.2 & \\
\hline 5 & Menaikkan Blow Head & 1,2 & 1,2 & \\
\hline 6 & Menggeser Blow tank ke hopper pasir & 2,1 & 2,1 & \\
\hline 7 & Pemanasan core & 40 & 40 & \\
\hline 8 & Menurunkan Puller & 0 & 1,4 & $\begin{array}{l}\text { Mengacu pada } \\
\text { simulasi }\end{array}$ \\
\hline 9 & Membuka core box & 2,8 & 2,8 & \\
\hline 10 & Mencukit tabung tengah & 2,3 & 0 & \\
\hline 11 & Mengangkat tabung tengah & 2,5 & 0 & \\
\hline 12 & Memukul Tabung tengah & 3,4 & 0 & \\
\hline \multirow[t]{2}{*}{13} & Mengambil core dari tabung tengah & 1,4 & 1,8 & \\
\hline & Total & 66 & 59,6 & \\
\hline
\end{tabular}

Jika performance rating 0,12 sedangkan untuk pekerja normal p dianggap 1 dan allowance nya 0,16 maka dapat diketahui waktu baku pembuatan core sebelum dan sesudah penambahan alat puller

Tabel 2 Waktu baku dan output standart per jam

\begin{tabular}{|r|l|c|c|}
\hline No & Uraian & Sebelum & Sesudah \\
\hline 1 & Waktu siklus & 66 & 59,6 \\
\hline 2 & Waktu Normal & 73,92 & 66,75 \\
\hline 3 & Waktu Baku & 85,75 & 77,43 \\
\hline 4 & Output Standart & 42 & 46 \\
\hline
\end{tabular}

Dari data yang ada dalam tabel 2, dapat dihitung kebutuhan manhour dan biaya tenaga kerja langsung jika jumlah order yang diterima perusahaan untuk tahun 2016 sebesar 11.207 dan tahun 2017 sebesar 11.794 unit. Gaji pokok perbulan untuk operator pada tahun 2016 adalah Rp 3.040.000 dan diestimasikan naik 10\% pada tahun 2017.

Tabel 3 Biaya tenaga kerja langsung pembuatan core sebelum dan sesudah investasi puller tahun 2016 dan tahun 2017

\begin{tabular}{llll}
\hline No & \multicolumn{1}{c}{ Uraian } & Tahun 2016 & Tahun 2017 \\
\hline 1 & Sebelum investasi puller & $\operatorname{Rp~77.027.259~}$ & $\operatorname{Rp~} 91.216 .134$ \\
2 & Sesudah investasi puller & $\operatorname{Rp~66.110.805~}$ & $\operatorname{Rp~78.579.075~}$ \\
& Penghematan & $\operatorname{Rp~} 10.916 .454$ & $\operatorname{Rp~12.637.059~}$ \\
\hline
\end{tabular}

Penghematan biaya tenaga kerja langsung yang diperoleh dari penambahan alat puller ini dianggap sebagai manfaat yang akan diterima oleh perusahaan. Manfaat lain yang akan diterima adalah nilai sisa dari peralatan setelah umur teknisnya berakhir. Pengeluaran yang harus ditanggung oleh perusahaan meliputi biaya investasi alat, biaya operasional, biaya perawatan serta biaya depresiasi. Aliran kas selengkapnya dapat dilihat dalam tabel 4 berikut 
Tabel 4 Rincian Aliran Kas

\begin{tabular}{|l|l|l|l|}
\hline No & \multicolumn{1}{|c|}{ Uraian } & Tahun 2016 & Tahun 2017 \\
\hline 1 & Kas Masuk & & \\
\hline & 1. Penghematan BTL & $\mathrm{Rp} 10.916 .454$ & $\mathrm{Rp} \mathrm{12.637.059}$ \\
\hline & 2. Nilai Sisa & & $\mathrm{Rp} 5.993 .500$ \\
\hline 2 & Kas Keluar & & \\
\hline & 1. Investasi & $\mathrm{Rp} 15.045 .000$ & \\
\hline & 2. Biaya Operasional & $\mathrm{Rp} \mathrm{389.267}$ & $\mathrm{Rp} 409.656$ \\
\hline & 3. Biaya Perawatan & $\mathrm{Rp} 180.000$ & $\mathrm{Rp} 180.000$ \\
\hline & 4. Depresiasi & $\mathrm{Rp} \mathrm{4.525.750}$ & $\mathrm{Rp} \mathrm{4.525.750}$ \\
\hline
\end{tabular}

Aliran kas yang ada dalam tabel 4 dijadikan data untuk melakukan analisis kelayakan menggunakan ekonomi teknik yang terdiri dari:

\section{A. Net Present Value}

Net present value merupakan perbedaan antara nilai sekarang dari keuntungan dan biaya biaya yang akan dikeluarkan. Rekapitulasi perhitungan nilai present worth keseluruhan dapat dilihat dalam tabel 5 dengan asumsi $\mathrm{i}=10 \%$

Tabel 5 Rekapitulasi Nilai Present Worth

\begin{tabular}{l|l|l|l}
\hline No & \multicolumn{1}{|c|}{ Uraian } & \multicolumn{1}{|c}{ Jumlah } & \multicolumn{1}{c}{ Present Worth } \\
\hline 1 & Penghematan biaya tenaga kerja & $\mathrm{Rp} \mathrm{23.553.513}$ & $\mathrm{Rp} \mathrm{20.367.414}$ \\
2 & Nilai Sisa & $\mathrm{Rp} \mathrm{5.993.500}$ & $\mathrm{Rp} \mathrm{4.953.028}$ \\
& Total PW Kas Masuk & $\mathrm{Rp} 15.045 .000$ & $\mathrm{Rp} \mathrm{25.320.442}$ \\
3 & Investasi & $\mathrm{Rp} 796.133$ & $\mathrm{Rp} \mathrm{15.045.000}$ \\
4 & Biaya operasional & $\mathrm{Rp} 360.000$ & $\mathrm{Rp} 689.575$ \\
5 & Biaya Perawatan & $\mathrm{Rp} \mathrm{9.051.000}$ & $\mathrm{Rp} 312.390$ \\
6 & Biaya Depresiasi & & $\mathrm{Rp} \mathrm{7.854.439}$ \\
& Total PW Kas Keluar & $\mathrm{Rp} \mathrm{23.904.252}$ \\
\hline
\end{tabular}

Dari data data yang ada di tabel 5 jika dimasukkan kedalam persamaan, maka nilai NPV nya adalah

$$
\begin{aligned}
\mathrm{NPV} & =\sum_{t=0}^{n} R(P / F, i \%, t)-\sum_{t=0}^{n} E(P / F, i \%, t) \ldots \\
& =\operatorname{Rp} 25.320 .442-\operatorname{Rp} 23.904 .252 \\
\mathrm{NPV} & =\operatorname{Rp} 1.416 .191
\end{aligned}
$$

\section{B. Internal Rate Return}

Metode IRR adalah suatu metode yang akan digunakan untuk mencari tingkat suku bunga terhadap pengembalian modal disaat NPV sama dengan 0atau dengan kata lain berapa tingkat bunga yang menyebabkan keseimbangan antara semua pengeluaran dan pemasukan pada periode tertentu. Dengan menggunakan bantuan program excell, nilai IRR nya didapat sebesar $16,08 \%$

$$
\begin{aligned}
& I R R=\sum_{t=0}^{n} R\left(\frac{P}{F}, i \%, t\right)-\sum_{t=0}^{n} E_{j}\left(\frac{P}{F}, i \%, t\right)=0 \\
& \text { Total penerimaan }(\mathrm{R}) \quad=\mathrm{Rp} 10.916 .454+\mathrm{Rp} 18,630.559 \\
& =\operatorname{Rp} 29.547 .013 \\
& \text { Present worth nya adalah } \quad=\mathrm{Rp} 23.230 .713 \\
& \text { Total pengeluaran }(\mathrm{E}) \quad=\mathrm{Rp} 20.140 .017+\mathrm{Rp} 5.115 .406 \\
& =\mathrm{Rp} 25.255 .539 \\
& \text { Present worth nya adalah } \quad=\mathrm{Rp} 23.229 .539
\end{aligned}
$$

Jika total Penerimaan dan total pengeluaran dikurangi maka akan menghasilkan nilai sebesar $=\operatorname{Rp} 23.227 .521-\operatorname{Rp} 23.230 .571$

$=\mathrm{Rp} 142$ (dianggap mendekati 0 karena pembulatan) 


\section{Pay Back Period (PBP)}

Pay back periode adalah waktu minimum yang dibutuhkan untuk mengembalikan investasi awal dalam bentuk aliran kas yang didasarkan dari total penerimaan dikurangi total semua biaya. Karena aliran kasnya bukan merupakan deret seragam, maka penghitungan pay back periode menggunakan persamaan 8 . Untuk memudahkan penghitungannya perlu kita tampilkan tabel kas bersih selama umur teknis seperti yang terlihat dalam tabel 6 .

Tabel 6 Perhitungan Kas Bersih

\begin{tabular}{cccccc}
\hline $\begin{array}{c}\text { Tahun } \\
\text { ke }\end{array}$ & Kas Masuk & Kas Keluar & Kas Bersih & $\begin{array}{c}\text { Investasi } \\
\text { Awal }\end{array}$ & Pengurangan \\
\hline 0 & & & & 15.045 .000 & \\
1 & 9.924 .148 & 4.631 .880 & 5.292 .268 & & 9.752 .732 \\
2 & 15.396 .294 & 4.227 .372 & 11.168 .922 & & $(1.416 .191)$ \\
\hline
\end{tabular}

Perhitungan kas masuk dan kas keluar berdasarkan nilai present worth dari masing masing kas tersebut. Sedangkan kas bersih diperoleh dari pengurangan antara kas masuk dengan kas keluar. Dari tabel 6 terlihat bahwa ditahun ke 1, hasil pengurangan antara investasi awal dengan kas bersih didapatkan hasil senilai Rp 9.752.732. Hasil ini jika dikurangi dengan nilai kas bersih di tahun ke 2 akan menghasilkan nilai negatif Rp 1.416.191. Ini berarti bahwa pay back periode untuk proyek investasi alat puller adalah diantara 1 tahun sampai 2 tahun. Untuk menghitung pay back periode secara tepat kita gunakan persamaan sehingga hasilnya adalah:

$$
\begin{aligned}
& \mathrm{PBP}=\mathrm{t}+\frac{b-c}{d-c} \times 12 \text { bulan } \\
& \mathrm{PBP}=1+\frac{R p 15.045 .000-R p 5.292 .268}{R p 16.461 .191-R p} 5.292 .268 \\
& \mathrm{PBP}=1 \text { tahun }+10,48 \text { bulan }
\end{aligned}
$$

\section{Analisa Sensitifitas}

Analisa sensitifitas ini digunakan untuk mengetahui sejauh mana perubahan paramater dalam investasi berdampak pada hasil yang sudah dihitung sebelumnya yang diakibatkan oleh perubahan situasi dan kondisi selama umur teknis. Analisa sensitifitas dilakukan dengan mengubah nilai dari suatu parameter pada suatu waktu untuk selanjutnya dilihat bagaimana pengaruhnya terhadap akseptabilitas suatu alternatif investasi.

Dalam penelitian ini parameter yang dilakukan perubahan adalah jumlah penerimaan dan pengeluaran selama umur teknis dengan menggunakan kategori optimis, moderat dan pesimis. Kategori optimis diasumsikan bahwa penerimaan naik sebesar $5 \%$ dan pengeluarannya tetap. Kategori Moderat jika diasumsikan penerimaan tetap dan pengeluaran turun 5\% sedangkan kategori pesimis jika penerimaan tetap sedangkan pengeluarannya naik 5\%. Perhitungan Analisa Sensitifitas selengkapnya dapat dilihat dalam Tabel 7.

Tabel 7 Perhitungan Analisa Sensitifitas

\begin{tabular}{lllllc}
\hline No & Uraian & Perhitungan Awal & $\begin{array}{l}\text { Kategori } \\
\text { Optimis }\end{array}$ & $\begin{array}{l}\text { Kategori } \\
\text { Moderat }\end{array}$ & $\begin{array}{l}\text { Kategori } \\
\text { Pesimis }\end{array}$ \\
\hline 1 & Penerimaan & 25.320 .442 & 26.586 .464 & 25.320 .442 & 25.320 .442 \\
2 & Pengeluaran & 23.904 .252 & 23.904 .464 & 22.709 .039 & 25.099 .464 \\
3 & Umur Teknis & 2 tahun & 2 tahun & 2 tahun & \\
4 & Suku Bunga & $10 \%$ & $10 \%$ & $10 \%$ & $10 \%$ \\
5 & NPV & 1.416 .191 & 2.683 .014 & 2.612 .265 & 221.840 \\
6 & IRR & $16,08 \%$ & $19,7 \%$ & $20,4 \%$ & $12,13 \%$ \\
7 & PBP & 1 th10,48bln & 1 th 9,3 bln & 1 th 9,25 bln & 1 th11,76 bln \\
\hline
\end{tabular}




\section{ANALISA HASIL}

Dari hasil pembahasan dan perhitungan mengenai aspek keuangan dalam rencana investasi peralatan alat puller ini bisa kita lakukan analisa sebagai berikut:

\section{A. Analisis Kelayakan}

Untuk mengukur tingkat kelayakan investasi dibutuhkan beberapa kriteria penilaian. Pada beberapa proyek investasi, penilaian kelayakannya dilihat dari beberapa aspek. Ada aspek lingkungan, aspek pasar dan pemasaran, aspek finansial dan lain sebagainya. Karena investasi yang akan direalisasikan oleh CV XYZ ini termasuk peralatan teknis dan juga hanya merupakan peralatan tambahan dari sebuah mesin yang sudah lama beroperasi, maka kriteria penilaian kelayakannya menyangkut aspek teknis, aspek safety dan aspek finansial. Kriteria untuk penilaian kelayakan investasi pada tugas akhir ini hanya membahas dari aspek finansial saja dengan menggunakan 3 kriteria yaitu NPV, IRR dan Pay Back Period.

Dari hasil perhitungan NPV dengan tingkat interest factor sebesar 10\%, didapat hasil sebesar $\mathrm{Rp}$ 1.416.191. Angka ini diperoleh dari pengurangan antara nilai present worth penerimaan dan nilai present worth pengeluaran selama 2 tahun yang menyesuaikan dengan umur teknis peralatan. Sesuai dengan beberapa literatur yang dijadikan referensi, Jika nilai NPV $>1$ maka investasi tersebut dianggap layak.

Dari perhitungan IRR nya, investasi alat puller ini mampu menghasilkan IRR sebesar $16,08 \%$. Nilai ini diatas nilai MARR yang sudah ditetapkan oleh pihak perusahaan yaitu sebesar $15 \%$. Dengan demikian investasi ini dianggap layak karena salah satu syarat kelayakan investasi adalah nilai IRR > nilai MARR.

Sedangkan untuk kriteria Pay back period nya membutuhkan waktu 1tahun 8,19 bulan. Artinya bahwa pengembalian biaya investasi peralatan puller ini masih dibawah umur teknis peralatan yang sudah ditetapkan yaitu selama 2 tahun. Jika pay back period suatu investasi kurang atau lebih kecil dari umur teknisnya, maka Investasi tersebut dianggap layak.

\section{B. Analisa Sensitifitas}

Analisa sensitifitas digunakan untuk melihat kelayakan suatu investasi jika beberapa parameter mengalami perubahan. Perubahan ini bisa dari sisi penerimaan atau juga bisa dari segi penegluaran. Dengan menggunakan tiga kategori yaitu optimis, moderat dan pesimis seperti yang sudah dibahas sebelumnya, maka tingkat kelayakan investasi nya secara lengkap dapat dilihat dalam tabel 8 .

\begin{tabular}{|c|c|c|c|c|}
\hline No & Uraian & Kategori & $\begin{array}{l}\text { Hasil } \\
\text { Perhitungan }\end{array}$ & $\begin{array}{l}\text { Tingkat } \\
\text { Kelayakan }\end{array}$ \\
\hline \multirow[t]{3}{*}{1} & NPV & Optimis & Rp 2.683.014 & Layak \\
\hline & & Moderat & Rp 2.612.265 & Layak \\
\hline & & Pesimis & $\mathrm{Rp} \quad 221.840$ & Layak \\
\hline \multirow[t]{3}{*}{2} & IRR & Optimis & $19,7 \%$ & Layak \\
\hline & & Moderat & $20,4 \%$ & Layak \\
\hline & & Pesimis & $12,13 \%$ & Tidak Layak \\
\hline \multirow[t]{3}{*}{3} & Pay Back Periode & Optimis & 1 th 9,3 bln & Layak \\
\hline & & Moderat & 1th $9,25 \mathrm{bln}$ & Layak \\
\hline & & Pesimis & 1 th 11,76 bln & Layak \\
\hline
\end{tabular}

Dari data data yang tersaji dalam tabel 8 terlihat bahwa ketiga kriteria penilaian kelayakan investasi hanya satu kriteria yang tidak layak yaitu IRR untuk kategori pesimis sedangkan kategori yang lain masih dianggap layak meskipun mengalami perubahan sebesar 5\%. 


\section{KESIMPULAN}

Dari hasil pengolahan data yang sudah dilakukan bisa ditarik beberapa kesimpulan yaitu:

1. Besarnya manfaat yang akan diterima oleh perusahaan jika merealisasikan investasi alat puller ini adalah sebesar Rp 29.547.013 selama 2 tahun. Manfaat ini diperoleh dari penghematan biaya tenaga kerja sebagai akibat dari peningkatan output produksi jika memasang alat puller dan juga nilai sisa peralatan yang akan diterima di akhir umur teknisnya. Sedangkan besarnya biaya yang harus dikeluarkan oleh perusahaan jika ingin memasang alat puller ini adalah senilai Rp 16.203.923. Biaya ini meliputi biaya investasi awal, biaya operasional serta biaya perawatan selama umur teknisnya.

2. Dari perhitungan kriteria kelayakan, didapat nilai NPV sebesar Rp 1.416.191, IRR sebesar 16,08 \% dan pay back period selama 1tahun 8,19 bulan. Dengan demikian bahwa investasi alat puller ini dianggap layak.

\section{DAFTAR PUSTAKA}

[1] Giatman,2006. Ekonomi Teknik, PT Rajagrafindo Perkasa, Jakarta.

[2] Hendrich, Mahdi. 2013. Analisis Perhitungan Harga Pokok Produksi Pada Usaha Peternakan Lele Pak Jay di Sukabangun II Palembang, Jurnal ILMIAH vol v no III.

[3] Kashmir\& Jakfar.2012 Studi Kelayakan Bisnis, Prenadamedia Group, Jakarta.

[4] Kusuma, Parama Tirta Wulandari Wening \& Mayasti, Nur Kartika Indah.2014. Analisa Kelayakan Finansial Pengembangan Usaha Produksi Komoditas Lokal, Mie Berbasis Jagung, Jurnal AGRITECH, vol 34 no 2 Mei.

[5] Manope, Billy Firman, Kindongan, Paulus \& Tawas, Hendra .2014 Analisa Kelayakan Usaha Komoditas Biji Pala Melalui Penilaian Aspek Finansial pada Pedagang Pengumpul Kios Candra di Pulau Siau, Jurnal EMBA, vol 2 no 4 Desember.

[6] Pujawan, Nyoman.2012. Ekonomi Teknik, Guna Widya, Surabaya.

[7] Rachman, Taufiqur.2013 Penggunaan Metode Work Sampling Untuk Menghitung Waktu Baku dan Kapasitas Produksi Karungan Soap Chip di PT SA, Jurnal Inovasi vol 9 no. 1.

[8] Rinawati, Dyah Ika, Puspitasari, Diana. Muljadi, Fatrin, 2012, Penentuan Waktu Standart Dan Jumlah Tenaga Kerja Optimal Pada Batik Cap ( Studi Kasus: IKM Batik Saud Effendy, Laweyan) Jurnal J@ti Undip,Vol VII no 3 September Semarang.

[9] Simarmata, Frins Apul, 2015, Studi Kelayakan Investasi Pengadaan Peralatan PT Pelabuhan Indonesia IV (Perserso) di Makasar, Tesis Program Magister Program Studi Manajemen Program Pasca Sarjana Universitas Udayana, Denpasar.

[10] Wignyosoebroto, Sritomo. 2006. Studi Gerak dan Waktu, Guna Widya, Surabaya. 